\title{
Paraplegia
}

\section{Spontaneous Intraperitoneal Vesical Rupture in Association with Neuropathic Bladder}

\author{
H. S. Watson, BS, D. J. Culkin, MD, ${ }^{2}$ J. S. Wheeler, Jr, MD, ${ }^{3}$ J. Mata, MD, ${ }^{1}$ \\ D. Venable, $\mathbf{M D}^{1}$ \\ ${ }^{1}$ Department of Urology, Louisiana State University Medical Center, Shreveport, \\ Louisiana, USA, ${ }^{2}$ Department of Urology, Veterans' Administration Hospital, Shreve- \\ port, Louisiana, USA, ${ }^{3}$ Division of Urology, Department of Surgery, Hines Veterans' \\ Administration Hospital, Hines, Illinois, USA.
}

\section{Summary}

Spontaneous bladder rupture in association with a neuropathic bladder is an uncommon but life-threatening occurrence with only 18 previously reported cases. We report spontaneous intraperitoneal bladder rupture in 2 tetraplegic patients, review the literature, and discuss the pathogenesis and management.

Key words: Neuropathic bladder; Tetraplegia; Intraperitoneal bladder rupture.

A traumatic or spontaneous intraperitoneal bladder rupture is uncommon (Stone, 1931; Bastable, 1959) and even rarer in association with a neuropathic bladder (Bliss et al., 1964; Howat, 1971). Upon review of the literature, only 18 cases of 'spontaneous' vesical rupture in association with neurogenic bladder have been reported (Bliss et al., 1964; Howat, 1971). We present 2 additional cases, discuss the diagnosis and management, and review the literature.

\section{Case report 1}

A 63-year-old tetraplegic male presented with septic, oliguric and azotemic and gave a history of abdominal discomfort for 24 hours. The past medical history included stage B carcinoma of the prostate treated 18 months prior to admission with curative external beam radiotherapy and a 9-year history of multiple sclerosis. The patient's neuropathic bladder was managed with an external catheter without unusual difficulty. Previous urodynamic assessments revealed detrusor hyperreflexia and no outflow obstruction.

Physical examination revealed a quiet, distended, tender abdomen with involuntary guarding and rebound tenderness. The white blood cell count was increased with a left shift. The patient was febrile and hypotensive. Upon urethral catheterisation, only a small amount of bloody efflux was noted. X-ray examination revealed a radiographic pattern compatible with ileus without intra-abdominal free air. The patient remained anuric even with appropriate hydration. Exploratory laparotomy revealed an intraperitoneal bladder rupture.

A small perforation in the dome of the urinary bladder was discovered with a large volume of turbid intraperitoneal fluid. The perforation was sutured in two layers after 
biopsy and debridement. The abdomen was irrigated, and suprapubic and urethral catheters, as well as intraperitoneal drains were inserted. The post-operative course was uneventful. Repeat urodynamics studies once again demonstrated detrusor hyperreflexia without evidence of anatomical or functional outflow obstruction. The patient was returned to his nursing home with instructions to continue with his previous bladder management.

\section{Case report 2}

A 55-year-old tetraplegic male presented to the emergency room acutely ill. The patient, 15 years previously, had been paralysed in a motor vehicle accident. He had not seen a physician in over 13 years. His urological management had consisted of external catheter drainage. The patient had not urinated for approximately 2 days prior to presentation, and only a small amount of blood was seen in the drainage bag.

On admission, the patient was confused and combative, tachycardic, febrile, and hypotensive. Abdominal examination revealed guarding and hypoactive bowel sounds. A Foley catheter was atraumatically inserted and a small amount of bloody, purulent urine was drained. Significant laboratory values included a white blood cell count of 15500 with a left shift, BUN of $96.7 \mathrm{mg} / 100 \mathrm{ml}$, creatinine of $6.4 \mathrm{mg} / 100 \mathrm{ml}$, and electrolytes demonstrating a hyperkalemic, hyperchloremic metabolic acidosis.

KUB showed a ground glass appearance of the abdomen with dilated, air-filled loops of small bowel displaced, or floating, to the midline, compatible with intraperitoneal fluid or ascites (Fig. 1). Retrograde cystography revealed intraperitoneal extravasation of contrast, and a CT scan showed a large pelvic abscess with prevesical extension (Fig. 2).

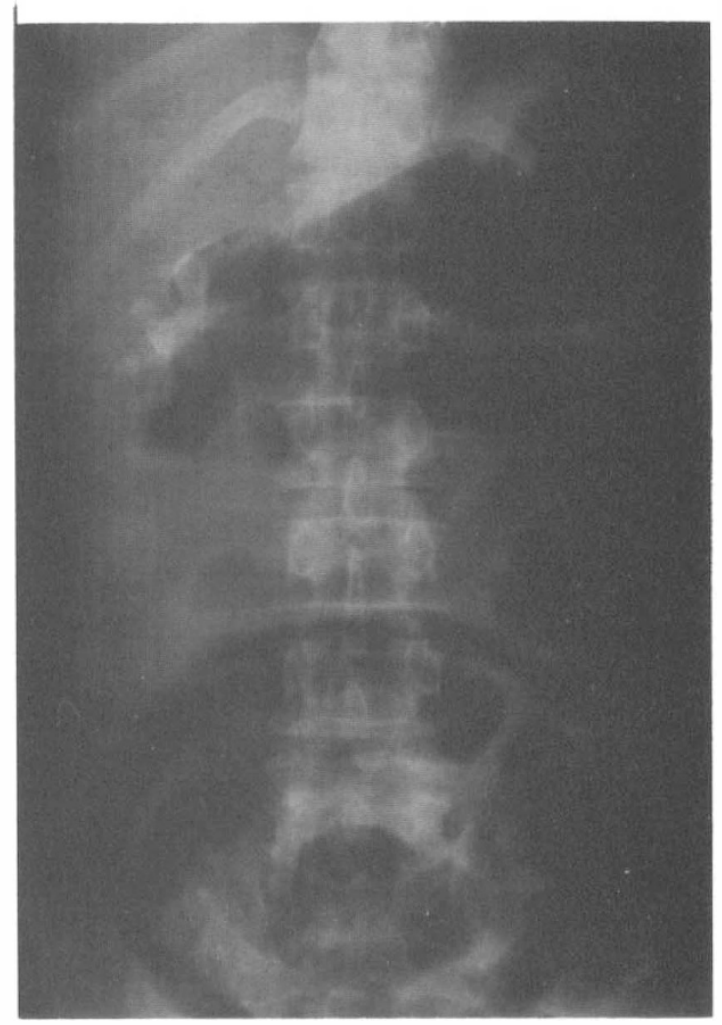

Figure 1 A supine plain film of the abdomen showing a staghorn calculus in the right renal unit and a ground glass appearance suggesting intraperitoneal fluid and air-filled 'floating' loops of small intestine. 


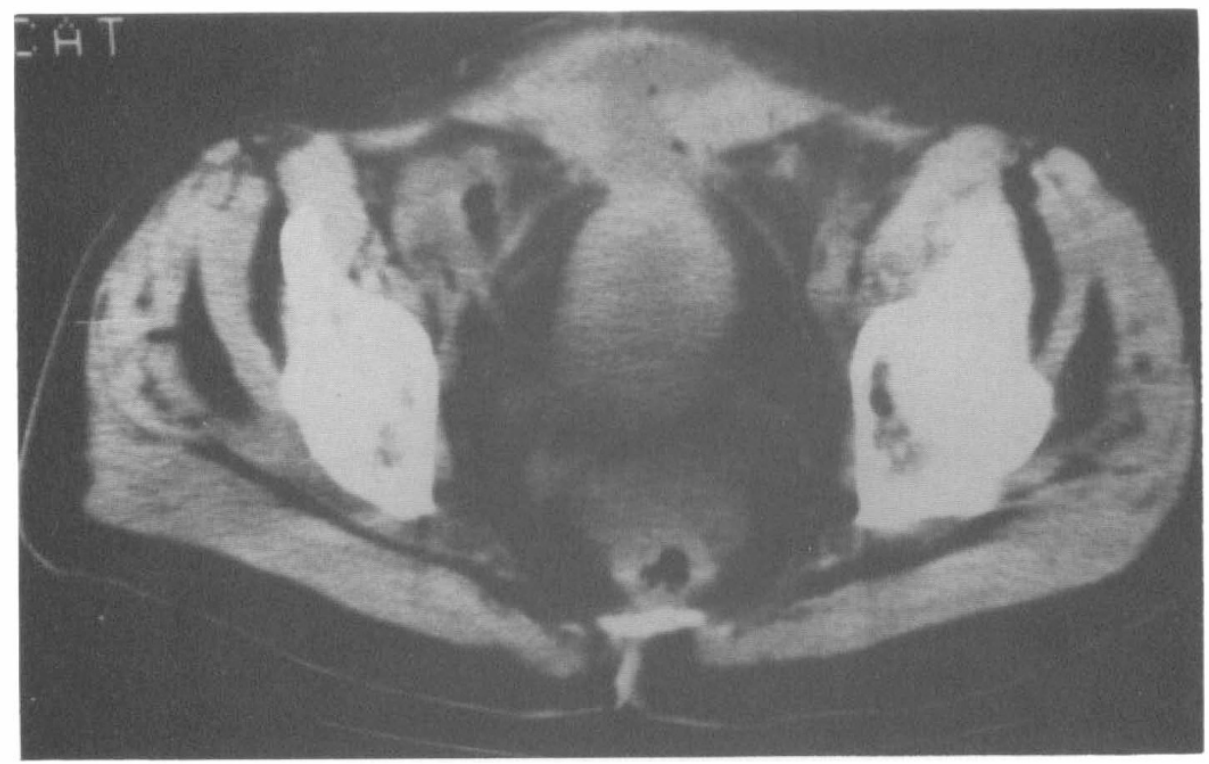

Figure 2 CAT scan film of pelvis showing bladder with fluid in the space of Retzius.

Exploratory laparotomy revealed a $2 \mathrm{~cm}$ intraperitoneal perforation along the left bladder wall. The entire dome of the bladder appeared to be necrotic with an additional prevesical collection of fluid and exudate. The edges of the perforation were trimmed and closed and the necrotic dome excised and closed. Histological examination of the excised necrotic bladder tissue revealed a squamous cell carcinoma. Penrose drains were placed intraabdominally and in the space of Retzius, and the bladder was drained suprapubically as well as transurethrally.

Post-operatively, the patient had a prolonged period of hospital care, but after 10 weeks of hospitalisation, he was afebrile, his vital signs stable and his condition had clinically improved. Upon discussion with the patient and family members, further therapy was refused, and he was discharged to the nursing home for intermediate supportive care.

\section{Discussion}

Spontaneous intraperitoneal vesical rupture was first defined in 1931 as disruption of the bladder wall without evidence of any extracorporeal force, i.e. trauma (Stone, 1931). The diagnosis is established by the history as well as cystographic and/or operative findings.

The classic presentation of intraperitoneal bladder rupture is a patient with an acute abdominal crisis, urinary retention and shock (Stone, 1931). Often, patients without neurological pathology say that they 'felt something give' as they were performing tasks that increased intra-abdominal pressure (i.e. voiding, defecating, etc.). The neurologically impaired patient's clinical presentation, however, can frequently be delayed or masked due to sensory and motor deficits and, therefore, is quite varied. In fact, the only clinical manifestations may be haemodynamic and those of an acute abdomen.

Only 18 cases of atraumatic or spontaneous intraperitoneal vesical rupture in association with a neuropathic bladder have been reported (Bliss et al., 1964; 
Howat, 1971). We add 2 cases of our own. Additive pathologies, i.e. radiation effects and squamous cell carcinoma, in addition to their neuropathic bladder, yet their neuropathic bladders were still thought to be either causative or to contribute to the vesical rupture. There were 8 males and 10 females and their ages ranged from 1 day to 75 years with a mean age of 49 years. Two patients suffered from recurrent spontaneous bladder rupture. Essential to a reduction of the high mortality and morbidity of spontaneous bladder rupture is a high index of suspicion and a familiarity with definitive diagnostic studies. Retrograde cystography provides the quickest and most accurate means for the diagnosis of spontaneous bladder rupture.

In this review, cystographic accuracy was $100 \%$ in the 8 cases in which it was utilised. However, if bowel or omentum becomes adherent to and seals off the bladder perforation, or an inadequate volume of contrast is instilled, a false negative study may result (Taylor, 1948). Because renal excretion of contrast material is slow, physiological and intravesical pressures often do not rise high enough to allow for significant extravasation, intravenous pyelography is less reliable for making a diagnosis. Cystoscopy is not necessary for the diagnosis of bladder rupture and may be misleading. Plain films of the abdomen usually show nonspecific changes. Rarely is intra-abdominal free air present unless it has been inadvertently instilled by urethral instrumentation. The so-called 'diagnostic catheter' that was initially advocated had fallen into disfavour. False positives with this latter test may result from blood clots or debris within an intact bladder (Garfinkle et al., 1976; Shaked et al., 1986; Taylor, 1948). The overall mortality was $21 \%$ in our review of intraperitoneal bladder rupture in association with a neuropathic bladder (Table). Mortality in cases of intraperitoneal bladder rupture has been reported as high as $92 \cdot 3 \%$ (Wilson, 1959) before $1900 ; 45 \cdot 4 \%$ to $47 \%$ from 1900 to 1959 (Wilson, 1959; Howat, 1971) and as low as $25 \%$ as recently as 1985 (Garfinkle et al., 1976). Thus, mortality rates for spontaneous bladder rupture have improved markedly in the post-antibiotic era, probably also due to better diagnostic procedures, more aggressive treatment and improved supportive and monitoring measures for the acute rupture as well as improved management for the often associated neurological voiding dysfunction.

Table 1 Spontaneous intraperitoneal vesical rupture in association with a neuropathic bladder

\begin{tabular}{lcll}
\hline $\begin{array}{l}\text { Pathogenesis of } \\
\text { neuropathy }\end{array}$ & $\begin{array}{c}\text { Incidence of } \\
\text { bladder wall } \\
\text { pathology }\end{array}$ & $\begin{array}{l}\text { Aetiology of } \\
\text { bladder wall } \\
\text { pathology }\end{array}$ & Mortality \\
\hline $\begin{array}{l}\text { Multiple sclerosis } \\
(\mathrm{N}=4)\end{array}$ & $(1 / 4) 25 \%$ & Radiation cystitis & $(0 / 4) 0 \%$ \\
$\begin{array}{l}\text { Spinal cord injury } \\
(\mathrm{N}=6)\end{array}$ & $(3 / 6) 50 \%$ & $\begin{array}{l}\text { Squamous cell } \\
\text { Carcinoma; cystitis; } \\
\text { abscess }\end{array}$ & $(2 / 6) 33 \%$ \\
$\begin{array}{l}\text { Cerebrovascular accident } \\
(\mathrm{N}=3)\end{array}$ & $(1 / 3) 33 \%$ & Abscess & \\
$\begin{array}{l}\text { Myelomeningocele } \\
(\mathrm{N}=2)\end{array}$ & $(1 / 2) 50 \%$ & Diverticulum & $(0 / 3) 0 \%$ \\
$\begin{array}{l}\text { Neurosyphilis } \\
(\mathrm{N}=2)\end{array}$ & $(1 / 2) 50 \%$ & Cystitis & $(1 / 2) 50 \%$ \\
\hline
\end{tabular}


In all, the mortality of the paraplegic/tetraplegic patient group in this review was 2 of 6 , or $33 \%$ (Table). In explanation, we note that these patients had decreased or absent visceral and somatic sensation (Crawford et al., 1971). Seven of 20 patients had documented bladder wall pathology, although in another 12 patients the subject was not addressed.

In our 2 cases, the cause of that bladder rupture may have been over-distention secondary to posterior urethral dysfunction related to infection. We believe it is reasonable to assume that both the bladder wall pathology and the posterior urethral obstruction were contributing factors in these cases and that urinary retention caused by posterior urethral dysfunction led to the perforation of an already weakened bladder wall.

Pre-operative neuropathic bladder management in this review was varied, but at least 4 patients had permanent indwelling urethral catheters. Two of these were noted to have had blocked Foley catheters upon presentation (Juul et al., 1985; Taylor, 1948).

Other therapeutic procedures should be carefully considered before patients are discharged with indwelling catheters (Ascoli, 1968). Clean intermittent selfcatheterisation with or without pharmacotherapy is an alternative to the chronic use of indwelling catheters (Lapides et al., 1972). It may be necessary to reassess bladder function with repeated urodynamic evaluation and to alter management surgically or pharmacologically, as indicated (Miller et al., 1965). Also, the use of intestinal segments for bladder augmentations or replacements may also be therapeutic alternatives in selected patients.

\section{Summary}

Spontaneous bladder rupture with a neuropathic bladder is rare, and carries a significant mortality rate. In a patient with an acute abdominal crisis and a neuropathic bladder, bladder rupture must be included in the differential diagnosis. Cystography is the most sensitive and specific pre-operative method for the diagnosis of this entity.

With an increased awareness of atraumatic vesical rupture and advances in supportive therapy, a continued decline in the mortality and morbidity of patients with spontaneous rupture of the urinary bladder is expected to occur.

\section{References}

Ascoli R 1968 The indwelling catheter in paraplegics. Paraplegia 6:17.

BASTABLE JRG, DE JODE LR, WARREN RP 1959 Spontaneous rupture of the bladder. British fournal of Urology 31:78.

Bliss BP, ClARK WGB, SAUNDERS M 1964 Recurring spontaneous rupture of the urinary bladder following subarachnoid haemorrhages. British fournal of Urology 51:446.

Brereton RJ, Philp N, BuyukPamukcu N 1980 Rupture of the urinary bladder in children. The importance of the double lesion. British fournal of Urology 52:15.

CraWford JP, Frankel HL 1971 Abdominal 'visceral' sensations in human tetraplegia. Paraplegia 9:153.

Desmond AD, Woolfenden KA, Evans CM I 983 The importance of UROdynamic investigation FOLLOWING SPONTANEOUS RUPTURE OF THE BLADDER. Fournal of Urology 129:140.

DixON CF, STROHL EL 1936 Spontaneous rupture of the urinary bladder. American fournal of Surgery 33:110.

Garfinkle SE, Chiu GW, Cohen SE, Wolfman EF JR 1976 Spontaneous perforation of the neurogenic urinary bladder. Western Fournal Medicine 124:64. 
HARding AE, Scott J, JefFERSon M 1977 Bladder rupture in multiple sclerosis. British Medical fournal 1:270.

Howat JM 1971 Urinary ascites complicating spina bifida. Archives of Disease in Childhood 46:105.

JuUl P, HoJHus H 1985 Spontaneous rupture of the urinary bladder. Scandinavian fournal of Urology and Nephrology 19:155.

Lapides J, Diokno AC, Silber SJ, Lower BS 1972 Clean intermittent self-catheterization in the treatment of urinary tract disease. Fournal of Urology 111:124.

MANN CM, LEAPE LL, HoldER RM 1974 Neonatal urinary ascites: A report of 2 cases of unusual etiology and a review of the literature. Fournal of Urology 111:124.

Miller H, Simpson CA, Yeates WK 1965 Bladder dysfunction in multiple sclerosis. British Medical Fournal 1:1265.

Shaked A, Meretyk S, Poke D, CAINe M 1982 Nontraumatic spontaneous rupture of the urinary bladder. Canadian Fournal of Surgery 29:107.

SMITH RB, KeTtLEWELL MG 1976 Rupture of the bladder diverticulum in multiple sclerosis. British Fournal of Urology 48:383.

STONE E 1931 Spontaneous rupture of the urinary bladder. Archives of Surgery 23:129.

TAYLOR RA 1948 Spontaneous rupture of the urinary bladder. British fournal of Urology 20:117.

THOMPSON IM, JoHNSON EL, Ross G JR 1965 The acute abdomen of unrecognized bladder rupture. Archives of Surgery 90:371.

Vaidyanathan S, Rao MS, Saleem A, Subudhi CL, Rajendran LJ, Shrinkhande VV 1979 Fatal intra-peritoneal bladder rupture due to blocked catheter in a paraplegic. Paraplegia 17:272.

WILSON LL 1959 Spontaneous rupture of the urinary bladder in a tabetic patient. British fournal of Urology 31:78. 